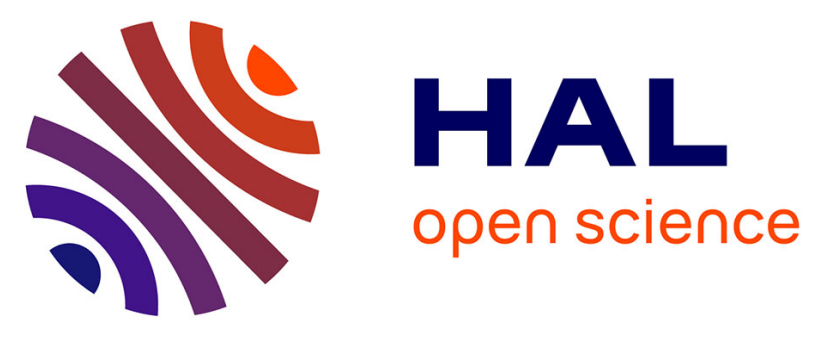

\title{
Using a Cooking Operation Simulator to Improve Cooking Speed in a Multiproduct Japanese Cuisine Restaurant
}

Takeshi Shimamura, Yoshihiro Hisano, Syuichi Oura, Tomoyuki Asakawa, Toshiya Kaihara, Nobutada Fujii, Tomomi Nonaka

\section{To cite this version:}

Takeshi Shimamura, Yoshihiro Hisano, Syuichi Oura, Tomoyuki Asakawa, Toshiya Kaihara, et al.. Using a Cooking Operation Simulator to Improve Cooking Speed in a Multiproduct Japanese Cuisine Restaurant. IFIP International Conference on Advances in Production Management Systems (APMS), Sep 2014, Ajaccio, France. pp.556-563, 10.1007/978-3-662-44736-9_67 . hal-01387931

\section{HAL Id: hal-01387931 \\ https://hal.inria.fr/hal-01387931}

Submitted on 26 Oct 2016

HAL is a multi-disciplinary open access archive for the deposit and dissemination of scientific research documents, whether they are published or not. The documents may come from teaching and research institutions in France or abroad, or from public or private research centers.
L'archive ouverte pluridisciplinaire HAL, est destinée au dépôt et à la diffusion de documents scientifiques de niveau recherche, publiés ou non, émanant des établissements d'enseignement et de recherche français ou étrangers, des laboratoires publics ou privés.

\section{(c)(1)}

Distributed under a Creative Commons Attribution| 4.0 International License 


\title{
Using a Cooking Operation Simulator to Improve Cooking Speed in a Multiproduct Japanese Cuisine Restaurant
}

\author{
Takeshi Shimamura',2, Yoshihiro HIsano ${ }^{2}$, Syuichi Oura ${ }^{2}$, Tomoyuki Asakawa ${ }^{2}$ \\ Toshiya Kaihara ${ }^{3}$, Nobutada Fujii ${ }^{3}$, and Tomomi Nonaka ${ }^{3}$, \\ ${ }^{1}$ Center for Service Research, National Institute of Advanced Industrial Science and \\ Technology, Tokyo, Japan \\ ${ }^{2}$ Ganko Food Service Co. Ltd., Osaka, Japan \\ ${ }^{3}$ Graduate School of System Informatics, Kobe University Kobe, Japan \\ Takeshi Shimamura, t-shimmura@aist.go.jp
}

\begin{abstract}
This study was conducted to improve the cooking speed in multiproduct Japanese cuisine restaurants using a cooking operation simulator. Traditionally, restaurants improve cooking speed through menu and cooking operation simplification because the cooking speed depends strongly on customer satisfaction and productivity. In recent years, customer requirements for restaurant menus have become diverse. A restaurant must evolve the menu and cooking operations to adapt to customer needs. Cooking systems of multiproduct restaurants can produce diverse menus, but the cooking speed is low. They should improve the cooking speed to improve customer satisfaction and productivity.

A cooking operation simulation was conducted to improve cooking speed by improving the kitchen layout, cooking machine capacity, and work plans. Simulation results show that cooking speed can improve: 1) working habits of crew chiefs should be changed to improve cooperation; 2) IE and QC should be introduced to resolve problems such as staff fatigue; 3 ) simulations should be conducted frequently to adapt to changing customer needs and changing contents of orders.
\end{abstract}

\section{Introduction}

Until the 1960s, dining out was a luxury enjoyed by wealthy people. Restaurants provided fine dishes to satisfy wealthy customers. For such occasions, they hired skillful chefs at high salaries to compete with other restaurants by offering fine dishes. Consequently, fine dining was expensive. The restaurant market remained small.

In the 1970s, some innovative Japanese restaurant companies introduced chain store operation systems to reduce restaurant costs and therefore prices. The system introduced factory production systems with a so-called "central kitchen" to reduce the number of kitchen staff members. In addition, the central kitchen was able to reduce the dependence on skillful chefs because demanding cooking processes were done at a central kitchen. In addition, chain store restaurants reduced the total menu items to simplify cooking processes [1] [2]. Especially, fast food and family restaurants made

adfa, p. 1, 2011.

(C) Springer-Verlag Berlin Heidelberg 2011 
strong efforts to introduce systems providing ordered items quickly because the cooking speed strongly affects customer satisfaction and productivity [3] [4].

In the 1980s, Japanese restaurants introduced information systems to improve cooking speeds further. For instance, point of sale (POS) systems that had been introduced into the CVS industry were introduced in restaurants [5] [6]. Until the introduction of POS systems, order information was written down on order sheets by service staff. Sheets were handed to the kitchen staff. A worker had to input each ordered item and a price when a customer checked out. In contrast, the POS system records order information, stores it on a POS server using a small order-entry device, and transmits it to the kitchen. A kitchen printer immediately issues an order sheet and a kitchen staff member cooks after referring to it. In addition, the POS cashier sums up the total of price using order information. Therefore, a service staff member need not convey an order sheet when receiving an order, and need not input a price when a customer checks out [5] [6].

The restaurant industry introduced cooking machines to simplify cooking operations. Sushi companies developed sushi makers. Before introduction of such machines, sushi was prepared by an experienced sushi chef. For that reason, sushi was expensive and preparation was slow. By contrast, a sushi maker prepares sushi automatically (a part time employee merely inserts raw fish), and serves it on a belt conveyer. The price of sushi dropped to that of fast food. Today, sushi has become a popular food for restaurant diners [7].

Dining out had become not a luxury but light leisure for Japanese customers by the introduction of new systems and technologies. As a result, the restaurant industry market size expanded rapidly. By the early 1990s, the restaurant industry had become a key industry in the Japanese economy. The Japanese restaurant market was approximately 30 trillion yen (300 billion US dollars), employing approx. 4 million staff workers [8].

However, as the market has expanded, the gap separating production systems and customer requirements has widened. As customers have experienced various dining experiences, their requirements have become diverse [9]. The chain store system has simplified menus and cooking operations. Restaurant companies understand the gap, but they cannot change or diversify menus because changing production systems and menus entails abandonment of the chain store system and production system.

Instead, Japanese restaurant companies have introduced low-price strategies to achieve breakthroughs. They accelerated investigation of restaurants to realize economies of scale, not introducing new production systems and menus to adapt to customer needs. That strategy saturated the Japanese restaurant market with many competitors. Many restaurant companies were bankrupted during the 1990s.

In the 2000s, the Japanese restaurant industry changed its policy from a "low price strategy" to "menu diversification". For instance, the largest providers increase menus from 3 to 21 categories [10]. That strategy satisfied customer requirements, but productivity declined because increased cooking speeds aggravated the sheet turnover ratio and increased the number of cooking staff. The restaurant industry must introduce new production systems.

The authors have introduced a cell production system to reduce labor costs and to reduce food production amounts at multiproduct Japanese restaurants [11]. The system concept combines machine production and manual work. In addition, the system 
is intended to reduce labor costs by enhancing labor elasticity. When a restaurant is rushed, many staff members work in the kitchen to prepare numerous and diverse orders. When the order number is reduced, a multi-skilled worker prepares dishes using cell equipment.

However, previous studies have revealed some problems. For instance, the study did not change the basic kitchen layout. The cell was placed in a vacant area to improve cooking operations but optimization of the kitchen layout was not considered. The entire kitchen layout is regarded as improving cooking operations. Moreover, the study did not measure cooking speed, although it is necessary for customer satisfaction, turnover ratio of table, and labor input.

To resolve the problems, a cooking operation simulator was developed to optimize the kitchen layout based on a food factory simulator [12]. The system simulates the cooking time of individual orders. Simulations are run several times using order data, labor input data, cooking-operation database, and a kitchen-layout database. Some kitchen layouts are designed based on the simulation results. A method of kitchen layout design using the simulator is demonstrated and discussed.

\section{Simulating Cooking Operation}

\subsection{Cooking operation simulator}

The cooking simulator system is developed to simulate the cooking time of orders using actual order information (Fig. 1). The system comprises a POS system, an attendance management system, a cooking-operation database, and a kitchen-layout database. Order information (Demand) is recorded by the POS system; the labor input (Supply) is measured by the attendance management system.

The cooking time of the multiproduct Japanese cuisine restaurant A (6 floors, 500 sheets, 2 washoku kitchens on the first floor and sixth floor, 1 sushi kitchen on the first floor, and 210 menu items) managed by restaurant company B (operating 100 Japanese cuisine restaurants in Osaka, Japan) is simulated. The average cooking time of orders at each cooking position $\left(T_{\mathrm{p}}\right)$ and total orders $\left(T_{\mathrm{a}}\right)$ are simulated as KPI of $[3][4][13]$.

Cooking times of 210 menus are measured by 22 cooking staff members and scorers to create a cooking-operation database of restaurant $\mathrm{A}$. To create the present kitchen layout database of restaurant $\mathrm{A}$, the location, size, front, and production capacity of the cooking machine are measured using a drawing sheet of restaurant A. Customer orders (484 orders), working hours (128 hours), and places of staff members (20 staff members) of restaurant A on 12, 8, 2013 are recorded by the POS system and the attendance management system to simulate the cooking time at restaurant A.

Based on these results, problems of the present kitchen layout are discussed by an experienced store manager (41 years old, 19 years of service at B), a grand chef (52 years old, 34 years of service at B) of restaurant A, and a kitchen planner (43 years old, 15 years of service at B). Two ideas for kitchen layout improvement at restaurant A were planned based on the results (plan A, plan B). Plan A maintains the present kitchens ( 2 washoku kitchens, 1 sushi kitchen). Plan B consolidates the 2 washoku 
kitchens to 1 kitchen on the first floor. $T_{\mathrm{p}}$ and $T_{\mathrm{a}}$ of plan $\mathrm{A}$ and $\mathrm{B}$ are simulated by the system to confirm the efficacy of plans $\mathrm{A}$ and $\mathrm{B}$.

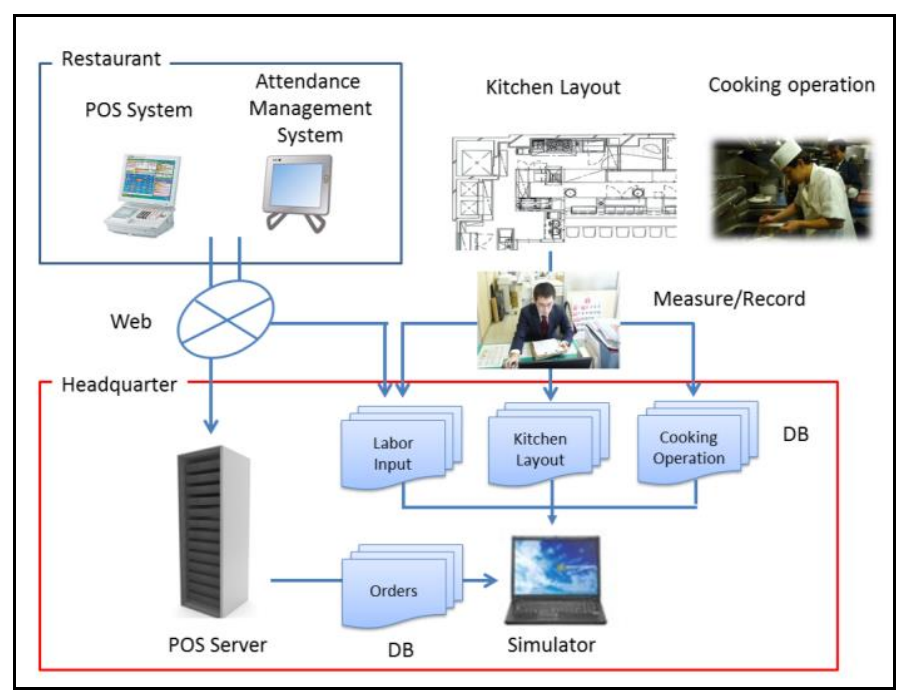

Fig. 1: Layout of the restaurant A's kitchen.

Based on those results, they again discussed effects and problems of the respective plans and designed a more efficient kitchen layout (plan C). The $T_{\mathrm{p}}$ and $T_{\mathrm{a}}$ of plan $\mathrm{C}$ are simulated to confirm the efficacy of plan $\mathrm{C}$. Then they were compared to the present layout, plan A, and plan B.

\section{Results and discussion}

\subsection{Results}

Table 1 and Table 2 present results of simulations. $T_{\mathrm{a}}$ of the present layout was 4.22 $\min (\mathrm{SD}=3.51 \mathrm{~min})$. Plan A was $4.81 \mathrm{~min}(\mathrm{SD}=3.18 \mathrm{~min})$. Plan B was $5.31 \mathrm{~min}$ $(\mathrm{SD}=3.28 \mathrm{~min})$. Plan $\mathrm{C}$ was $3.75 \mathrm{~min}(\mathrm{SD}=2.67 \mathrm{~min})$.

Table 1: Average cooking time of simulations (min)

\begin{tabular}{l|lrrrr}
\hline \multicolumn{2}{l}{ Cooking Position } & Present & Plan A & Plan B & \multicolumn{2}{c}{ Plan C } \\
\hline \multirow{7}{*}{$T_{\mathrm{p}}$} & Sushi, Sashimi & 3.73 & 5.06 & 5.08 & 3.47 \\
\cline { 2 - 6 } & Noodles & 4.79 & 4.47 & 4.36 & 4.11 \\
\cline { 2 - 6 } & Tray Service & 2.08 & 2.79 & 3.68 & 2.18 \\
\cline { 2 - 6 } & Fried Foods & 4.76 & 5.93 & 6.51 & 5.00 \\
\cline { 2 - 6 } & Simmered Foods & 4.93 & 5.48 & 6.38 & 4.88 \\
\cline { 2 - 6 } & Baked Foods & 5.31 & 5.13 & 5.96 & 4.78 \\
\cline { 2 - 6 } & Salads, Small Dishes & 6.50 & 4.34 & 6.37 & 3.74 \\
\hline$T_{\mathrm{a}}$ & & 4.22 & 4.81 & 5.31 & 3.75 \\
\hline
\end{tabular}


Table 2: Standard deviation of the simulation (min)

\begin{tabular}{l|lrrrr}
\hline \multicolumn{2}{l}{ Cooking Position } & Present & Plan A & Plan B & \multicolumn{2}{l}{ Plan C } \\
\hline \multirow{7}{*}{$T_{\mathrm{p}}$} & Sushi, Sashimi & 2.28 & 3.47 & 3.03 & 1.85 \\
\cline { 2 - 6 } & Noodles & 1.80 & 1.39 & 1.05 & 1.35 \\
\cline { 2 - 6 } & Tray Service & 1.60 & 2.33 & 3.19 & 1.75 \\
\cline { 2 - 6 } & Fried Foods & 3.30 & 2.24 & 2.74 & 2.34 \\
\cline { 2 - 6 } & Simmered Foods & 2.35 & 2.53 & 3.37 & 2.80 \\
\cline { 2 - 6 } & Baked Foods & 0.35 & 0.58 & 1.25 & 0.56 \\
\cline { 2 - 6 } & $\begin{array}{l}\text { Salads, Small Dish- } \\
\text { es }\end{array}$ & 7.33 & 4.35 & 4.90 & 5.22 \\
\hline$T_{\mathrm{a}}$ & & 3.51 & 3.18 & 3.28 & 2.67 \\
\hline
\end{tabular}

\subsection{Discussions}

First, the respective problems and efficacies of plan A and plan B are discussed. Both plans A and B were insufficient to improve $T_{\mathrm{a}}$, although the plans were designed by experienced staff members. Long experience and diverse skills are important factors supporting layout design, but both plans based on their heuristics were insufficient to enhance cooking time.

Three reasons explain why $T_{\mathrm{a}}$ of plans $\mathrm{A}$ and $\mathrm{B}$ worsened compared to the present layout: 1) reduction of cooking positions, 2) increasing work-load ratio because of changing work plans, and 3) increasing work-load ratio because of changing cooking equipment.

1) $T_{\mathrm{p}}$ of sushi and sashimi worsened because of the reduction of cooking positions. Both plans A and B reduced 1 sushi and sashimi cooking position because both plans were aimed at consolidating the washoku kitchen located at the first floor. The main washoku kitchen of restaurant $A$ is located on the sixth floor. The sub washoku kitchen is located at the first floor, although the main floor of restaurant A is located on the first floor.

2) $T_{\mathrm{p}}$ of the tray service worsened because of increasing work load. Both plan A and B added noodle-cooking operation to tray service staff because $T_{\mathrm{p}}$ of noodles was sluggish compared to tray service, and tray service of sub washoku kitchen was placed next to noodle boiler.

Instead, $T_{\mathrm{p}}$ of noodle of both plans $\mathrm{A}$ and $\mathrm{B}$ was improved compared to the present layout because of the work plan redesign. However, $T_{\mathrm{p}}$ will worsen if staff members of tray service do not help with noodle cooking. An alternative solution should be introduced to improve $T_{\mathrm{p}}$ of the position.

3) $T_{\mathrm{p}}$ of both simmered and fried foods worsened because of cooking machine replacement. Both plan A and B moved the fryer and stove burner from the sixth floor to the first floor to save conveyance operations from the sixth floor to the first floor by lift. Although the conveyance process was eliminated, the work load of staff members of both positions worsened because the work loads of staff members at simmered food and fried food areas increased.

However, $T_{\mathrm{p}}$ of salads and small dishes of both plans A and B were improved. Both plans $\mathrm{A}$ and $\mathrm{B}$ moved the position to the first floor to save conveyance operations 
from the sixth floor to the first floor by lift. Different from simmered and fried foods, salads and small dishes can cook and stock using idle time. Therefore, they need not cook when they receive orders.

Second, the efficacy and problems of plan $\mathrm{C}$ are discussed based on the problem categories. Plan C improved $T_{\mathrm{a}}$ compared to the present layout, and plans A and B. Plan $\mathrm{C}$ was designed based on the simulation results. Therefore, plan $\mathrm{C}$ was redeemed to resolve problems of plans A and B.

1) $T_{\mathrm{p}}$ of sushi and sashimi improved compared to present layout, plan A, and plan B. Plan C did not reduce sushi and sashimi cooking positions to maintain $T_{\mathrm{p}}$ of sushi and sashimi. Moreover, Plan $\mathrm{C}$ moved the sashimi cooking position from the washoku kitchen at the sixth floor to sushi kitchen to improve its $T_{\mathrm{p}}$. Results show that staff members of sushi and sashimi cooking positions increased from 3 to 4 ; their work load was reduced.

2) $T_{\mathrm{p}}$ of noodles maintained improvement compared to present layout, and plans $\mathrm{A}$ and B. Plan C replaced the work plan of tray service staff, and changed the kind of noodle boiler to enhance $T_{\mathrm{p}}$ of noodles. Results show that improvement of $T_{\mathrm{p}}$ was retained, although plan $\mathrm{C}$ stopped noodle-cooking support by tray service staff.

Nevertheless, $T_{\mathrm{p}}$ of tray service was not improved despite work plan replacements. The work load of tray service seemed to increase because $T_{\mathrm{p}}$ of sushi, sashimi, noodles, simmered foods, baked foods, salads, and small dishes were improved, and dishes flooded to the position of plan C did not increase the total number of staff members.

3) $T_{\mathrm{p}}$ of simmered foods improved compared to the present layout. Plan C increased the number of stove burners compared to the present layout to enhance cooking capacity. In addition, Plan C cleared the wall located between the sushi and washoku kitchen on the first floor to enhance cooperation between sushi and washoku staff members to assist one another when they had free time. Changing the layout, work plans, and increasing the cooking capacity are measures that boost the $T_{\mathrm{p}}$ of both positions.

However, $T_{\mathrm{p}}$ of fried foods was not improved even though plan C increased the number of fryers, and cleared the wall separating the sushi and washoku kitchen areas. Simmered foods are cooked dish-by-dish using a pan. Therefore, the cooking time depends strongly on the total number of stove boilers and staff members. Different from simmered foods, many fried foods are cooked simultaneously using fryers. Therefore, the cooking time has nothing to do with the total number of staff members. Moreover, the cooking speed depends strongly on ingredients. For instance, the cooking time of sliced vegetables such as pumpkin for fried foods is $3 \mathrm{~min}$, that of eggplant is $2 \mathrm{~min}$, and that of shrimp is $1.5 \mathrm{~min}$. Extension of fryers does not necessarily improve the cooking speed of fried foods.

As discussed above, kitchen design based on simulator results can improve the cooking time of multiproduct Japanese cuisine restaurant, but some critical problems remain.

First, Japanese cuisine chefs shun mutual cooperation because of their pride and habits. They believe that if a chef is supported by another chef, then the former must be regarded as "less-skilled" [12]. Moreover, sushi and washoku chefs dislike working together because they belong to different guilds. In Japan, sushi and washoku 
guilds have existed for more than 300 years. They have avoided copying and sharing their respective techniques. Such a historical reason prevents them from working together. They should be educated to change from a pride-based working system to a CS-based working system. Restaurant companies should produce a new training system for staff members, instead of a guild-based training system.

Second, results of simulation should be applied to actual restaurants. Although plan C improves $T_{\mathrm{a}}$, and $T_{\mathrm{p}}$ of sushi, sashimi, noodles, simmered foods, baked foods, salads, and small dishes, the results are only reflective of the simulation. Other factors affect the cooking speed such as the total number of available kitchenware such as dishes and pots, and operational impediments such as complaints and mistakes, and fatigue of staff members. Appropriate methods such as IE methods, behavior measures, and QC activities must be introduced to resolve those problems [14],[15].

Third, the redesign of work plans and work scheduling should be conducted each time the menu is changed. Multiproduct restaurants frequently change menus to tune the line up for customer requirements. For instance, the Japanese cuisine course "Kaiseki" changes the menu every month. In addition, the operation change should be discussed at turn of the year because contents of orders differ among seasons.

\section{Conclusions}

This study was undertaken to improve cooking times at multiproduct Japanese cuisine restaurants by introducing a cooking operation simulator. The cooking times of dishes at restaurant $\mathrm{A}$ were simulated using order data recorded by a POS system of restaurant A, with labor input recorded by input attendance management system of restaurant A. Results show that the cooking times of dishes can improve the work plan redesign, cooking machine placement, and changing kitchen layout. To realize simulation results at an actual restaurant, 1) working habits of chefs should be changed, 2) some other methodology such as IE and QC should be introduced to resolve some other problems, and 3) simulations should be conducted frequently to adapt to changing customer needs and changing order contents.

\section{Acknowledgements}

This study was partially supported by the Project of Service Science from JST/RISTEX for Service Science in 2013, and as a joint study with the Center for Service Research, National institute of Advanced Industrial Science and Technology (AIST).

\section{References}

1 Mariani, J.F.: America Eats Out, An Illustrated History of Restaurants, Taverns, Coffee Shops, Speakeasies, and Other Establishments That Have Fed Us for 350 Years, William Morrow and Co. (1991)

2 Chase, R.B., Apte, U.M.: A history of research in service operations: What's 
the big idea?, Journal of Operations Management 25(2), 375-386 (2007)

Davis, M.M., Maggard, M.J.: An analysis of customer satisfaction with waiting times in a two-stage service process. Journal of Operations Management 9(3), 324-334 (1990)

4 Luo, W., Liberatore, M.J., Nydick, R.L., Chung, Q.B., Sloane E.: Impact of process change on customer perception of waiting time: a field study. Omega 32(1), 77-83 (2004)

5 Swart, W.: A microcomputer network to enhance restaurant productivity. Computers \& Industrial Engineering 11(1), 430-433 (1986)

6 Stein, K.: Point-of-sales systems for foodservice. Journal of the American Dietetic Association 105(12), 1861-1863 (2005)

7 Ngai, E.W.T., Suk, F.F.C., Lo, S.Y.Y.: Development of an RFID-based sushi management system: the case of a conveyor-belt sushi restaurant. International Journal of Production Economics 112(2), 630-645 (2008)

8 Takenaka, T., Shimmura. T., Ishigaki, T., Motomura, Y., Ohura, S.: Process management in restaurant service - a case study of Japanese restaurant chain -. Proceeding of International Symposium on Scheduling 191-194 (2011)

9 Takenaka, T., Shimmura, T.: Practical and Interactive Demand Forecasting Method for Retail and Restaurant Services. Proceeding of International Conference Advances in Production Management Systems No. 3-4:2, (2011)

10 Yoshinoya HP Retrieved April 19, 2014, from http://www.yoshinoya.com/menu/

11 Shimmura, T., Takenaka, T., Ohura, S.: Improving productivity and labor elasticity at multiproduct Japanese cuisine restaurant introducing cell production system. Proceeding of International Conference Advances in Production Management Systems 11-17 (2013)

12 Fujii, N., Kaihara, T., Uemura, M., Nonaka, T., Shimmura, T.: Facility Layout Planning of Central Kitchen in Food Service Industry - Application to the real-scale problem. Proceeding of International Conference Advances in Production Management Systems 33-40 (2013)

13 Shimmura, T., Takenaka, T., Akamatsu, M.: Real-time process management system in a restaurant by sharing food order information. Proceeding of International Conference on Soft Computing and Pattern Recognition 703-706 (2009)

14 Ueoka, R., Shimmura, T., Tenmoku, R., Okuma, T., Kurata, T.: Introduction of Computer Supported Quality Control Circle in Japanese Cuisine Restaurant. First International Conference on Human Side of Service 6632-6641 (2012)

15 Tenmoku, R., Ueoka, R., Makita, T., Shimmura, T., Takehara, M., Tamura, S., Hayamizu, S., Kurata, T.: Service-Operation Estimation in a Japanese Restaurant Using Multi-Sensor and POS Data. Proceeding of International Conference Advances in Production Management Systems No. 3-4:1 (2011) 